\title{
Transcranial Doppler monitoring guided by cranial two-dimensional ultrasonography
}

\author{
Etienne J. Couture, MD, FRCPC • Georges Desjardins, MD, FRCPC, FASE • \\ André Y. Denault, MD, FRCPC, PhD, FASE
}

Received: 7 April 2017/Revised: 25 April 2017/Accepted: 2 May 2017/Published online: 16 May 2017

(c) Canadian Anesthesiologists' Society 2017

\section{To the Editor,}

Transcranial Doppler (TCD) imaging was introduced in 1982 as a noninvasive tool to evaluate the velocity of blood flow in the basal cerebral arteries. ${ }^{1}$ Since then, TCD has been used in a wide variety of situations, including detection of vasospasm after subarachnoid hemorrhage, finding microemboli during cardiac surgery, and intracranial pressure monitoring. Transcranial Doppler uses low frequency $(2 \mathrm{MHz})$ focused pulsed waves to insonate major cerebral vessels. The red blood cell velocity can be calculated by integrating the emitted and reflected frequencies along with the angle subtended by the respective ultrasonic beam and blood flow directions.

Transcranial Doppler monitoring can be easily performed through the temporal window for the arteries of the circle of Willis, submandibular window for the distal internal carotid artery, transorbital window for the ophthalmic artery, and suboccipital window for the vertebral and basilar arteries. The skull is composed of two layers of compact bone separated by a porous diploë

Electronic supplementary material The online version of this article (doi:10.1007/s12630-017-0898-9) contains supplementary material, which is available to authorized users.

E. J. Couture, MD, FRCPC

Critical Care Program, Université de Montréal, Montreal, QC, Canada

G. Desjardins, MD, FRCPC, FASE

Department of Anesthesiology, Montreal Heart Institute,

Université de Montréal, Montreal, QC, Canada

A. Y. Denault, MD, FRCPC, PhD, FASE ( $\square)$

Department of Anesthesiology and Critical Care, Montreal Heart Institute, Université de Montréal, Montreal, QC, Canada

e-mail: andre.denault@umontreal.ca layer that allows propagation of ultrasound waves by creating an acoustic interface. ${ }^{2}$ Nevertheless, in up to $38 \%$ of patients, Doppler signals cannot be acquired because of an inadequate temporal bone acoustic window. ${ }^{3}$ Blind placement of a TCD probe can be time consuming, and an inadequate signal might result from an insufficient temporal bone window. The use of two-dimensional (2D) cranial ultrasonography has the potential to facilitate localization of the temporal acoustic window prior to TCD probe placement.

The technique involves localizing the temporal acoustic window as the thinner part of the temporal bone just above the zygomatic arch (Figure). ${ }^{1}$ This area can be located either in the anterior part of the temporal bone close to the vertical portion of the zygomatic bone or, more frequently, posteriorly and close to the pinna of the ear. Any transthoracic or handheld low frequency transducer probe (1-2 MHz) can be used by directing the marker on the probe toward the occiput. The gain and depth $(14-18 \mathrm{~cm})$ are adjusted to localize the bony structures. The contralateral cranial bone is first located in the far field, and in the mid-field region, the petrous ridge can be identified posteriorly and the sphenoid wing anteriorly. The carotid siphon and foramen lacerum can be localized anteriorly. The cerebral falx and cerebral peduncle can be localized in the middle of the field with the mesencephalic brainstem (appearing as a butterfly shape surrounded by the echogenic basal cisterns) in the horizontal axial plane parallel to the orbitomeatal line. ${ }^{4}$ Doppler imaging (scale $24 \mathrm{~cm} \cdot \mathrm{sec}^{-1}$ ) allows identification of the major vascular structures. Depth and direction of flow are the main characteristics of the Doppler signal that help to differentiate the various vessels. ${ }^{5}$ The identification of the vascular structures usually takes less than one minute. Transcranial Doppler is then positioned and adjusted. 
A
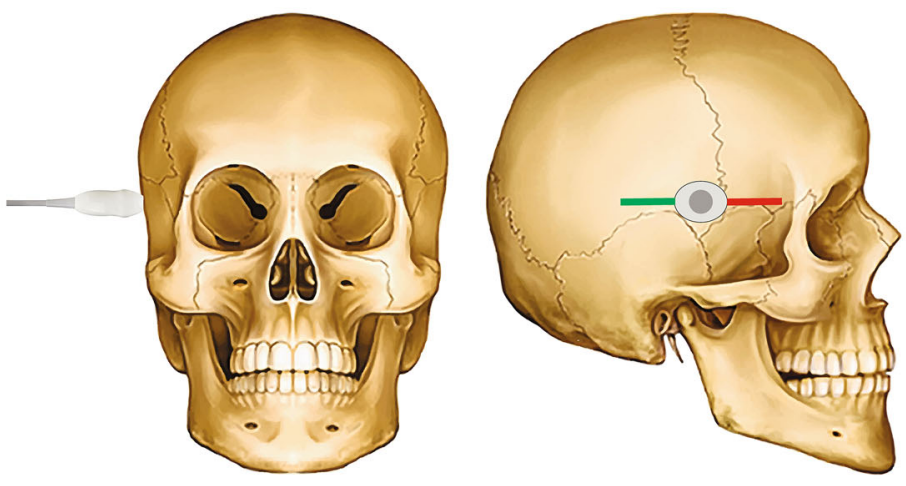

\section{C}

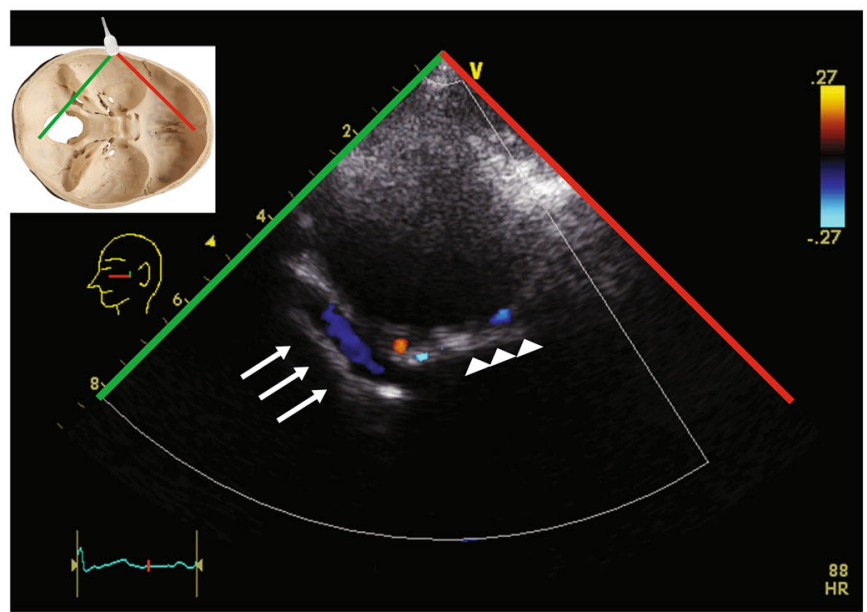

B

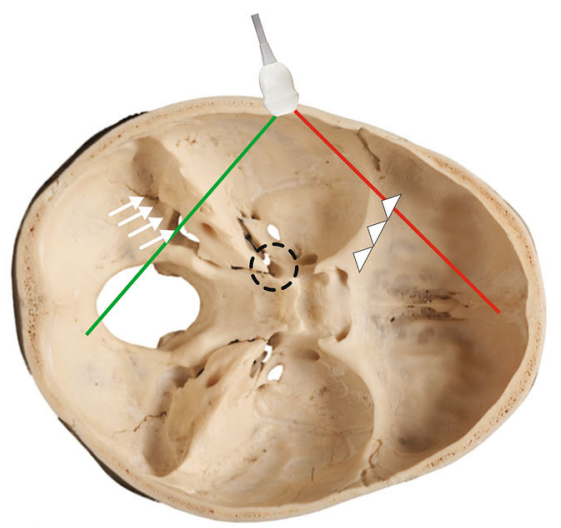

D

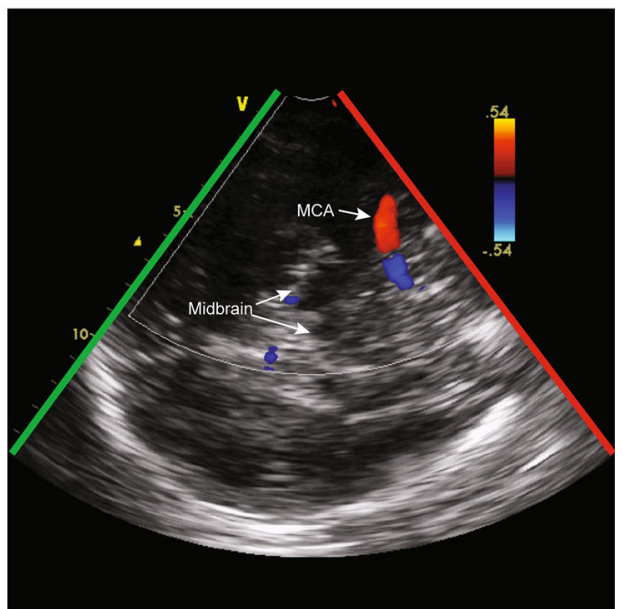

Figure Cranial two-dimensional (2D) ultrasonography technique to localize cerebral basal vessels. Step 1: Position the ultrasound probe over the temporal area in an axial orientation with the marker pointing toward the occiput (Figure A). Step 2: Using 2D imaging, initially adjust the display depth in order to see the opposite skull border (arrows). Scan in a cranial to caudal direction to identify the intracranial bone artefacts: contralateral skull, foramen lacerum (dotted circle), petrous ridge (arrows), and sphenoid bone (triangles) (Figs B, C). Step 3: Use colour Doppler with a low Nyquist limit $\left(24 \mathrm{~cm} \cdot \mathrm{sec}^{-1}\right)$ to augment the identification of blood flow signals of the left middle cerebral artery and the right middle

Since 2015, the above TCD technique has been used at our institution as part of a multimodal neurologic monitoring strategy. We recently reviewed our last 100 consecutive patients in the transesophageal echocardiography/hemodynamic database of the Montreal Heart Institute (previously approved by the local ethics and research committee [\#11-1277]).

Ninety-five of these patients had at least an adequate unilateral temporal bone window available for TCD monitoring. An adequate bilateral window was found in 70 patients, and in five patients, neither a right nor a left temporal bone window was present and TCD could not be used. cerebral artery (Figure D). The anterior cerebral artery can be seen at a depth of $60-75 \mathrm{~mm}$ with flow directed away from the anterior tilted probe. The middle cerebral artery can be seen at a depth of 40-65 mm with flow directed towards the perpendicularly oriented probe. The posterior cerebral artery can be localized at a depth of 55-70 $\mathrm{mm}$ with flow directed toward the posteriorly tilted probe. Step 4: Position the transcranial Doppler in the acoustic window with the same probe orientation. (Adapted with permission from: Denault A, Vegas A, Lamarche $Y$, Tardif JC, Couture P. Basic Transesophageal and Critical Care Ultrasound. CRC Press - Taylor \& Francis Group; 2017).

This novel report describes the use of 2D cranial ultrasound to facilitate TCD. Use of this technique to identify the temporal acoustic window can facilitate TCD monitoring in most patients. As the reported failure rates in TCD monitoring are quite high, ${ }^{3}$ adding cranial 2D ultrasonography to optimize placement of the TCD probe might be beneficial without being time consuming. Further studies are required to compare the yield of positioning conventional $v s$ echo-guided TCD probes.

Conflicts of interest None declared.

Editorial responsibility This submission was handled by Dr. Hilary P. Grocott, Editor-in-Chief, Canadian Journal of Anesthesia. 
Disclosures/funding sources None.

\section{References}

1. Aaslid R, Markwalder TM, Nornes $H$. Noninvasive transcranial Doppler ultrasound recording of flow velocity in basal cerebral arteries. J Neurosurg 1982; 57: 769-74.

2. Rigamonti A, Ackery A, Baker AJ. Transcranial Doppler monitoring in subarachnoid hemorrhage: a critical tool in critical care. Can J Anesth 2008; 55: 112-23.
3. Del Brutto OH, Mera RM, de la Luz Andrade M, et al. Temporal bone thickness and texture are major determinants of the high rate of insonation failures of transcranial Doppler in Amerindians (the Atahualpa Project). J Clin Ultrasound 2016; 44: 55-60.

4. D'Andrea A, Conte M, Cavallaro $M$, et al. Transcranial Doppler ultrasonography: from methodology to major clinical applications. World J Cardiol 2016; 8: 383-400.

5. Caricato A, Pitoni S, Montini L, Bocci MG, Annetta P, Antonelli $M$. Echography in brain imaging in intensive care unit: state of the art. World J Radiol 2014; 6: 636-42. 